Original Research Paper

\title{
Hypoxia-Inducible Factor $1 \alpha$ Expression in Chorionic Tissue and Decidua of Women with Spontaneous Abortion at the First Trimester of Pregnancy
}

\author{
E.V. Mashkina, K.A. Kovalenko and E.V. Butenko
}

Southern Federal University, Rostov-on-Don, Russia

\author{
Article history \\ Received: 31-08-2014 \\ Revised: 07-09-2014 \\ Accepted: 01-10-2014 \\ Corresponding Author: \\ E.V. Mashkina, \\ Southern Federal University, \\ Rostov-on-Don, Russia \\ Email: lenmash@mail.ru
}

\begin{abstract}
Oxygen-regulated genes expression has important role in preimplantation embryonic metabolism regulation. Hypoxia Inducible Factor (HIF) regulated by hypoxia oxygen tension is crucial for placenta development. But the data about its role in spontaneous abortion is very poor. Thus, we aimed to determine an expression level of $H I F-1 \alpha$ in chorionic tissue and decidua at pregnancy. Samples of chorionic tissue and decidua were taken after surgical termination of normally progressing pregnancies in 5-9 week of gestation $(\mathrm{n}=8)$ and spontaneous abortion in 59 week of gestation $(\mathrm{n}=9)$. $H I F-1 \alpha$ expression was analyzed using semiquantitative reverse transcription-polymerase chain reaction. Compared with decidual tissue, the expression of $H I F-1 \alpha$ was increased in chorionic tissue in condition of normally progressing pregnancy. $H I F-1 \alpha$ expression in samples of both tissues is equal in spontaneous abortion. In same time the expression of $H I F-1 \alpha$ was decreased (1,5 fold) in chorionic tissue for spontaneous abortion compared with control group. The results demonstrated that low $H I F-1 \alpha$ expression level in chorionic tissue can be associated with spontaneous abortion in first trimester of pregnancy.
\end{abstract}

Keywords: Spontaneous Abortion, HIF-1, Gene Expression, Chorionic Tissue

\section{Introduction}

About $15 \%$ of all human pregnancies end in spontaneous abortion before 12 weeks of gestation. The pathophysiology of pregnancy loss is complicated and poorly understood. Major part of the pregnancy loss causes remains unexplained after comprehensive study. Immunity, angiogenesis, apoptosis-related genes are involved in pathogenesis. The aberrant maternal inflammation associated with spontaneous abortion is closely linked to deficient placental perfusion (Renaud et al., 2011).

Early stages of the mammalian placenta development are regulated by oxygen tension and the hypoxic uterine environment (Giaccia et al., 2004). A hypoxic environment is essential for proper embryonic development. Low oxygen appears to prevent trophoblast differentiation into an invasive phenotype. This physiological switch in oxygen tension is a prerequisite for proper placental development (Patel et al., 2010). Low oxygen tension induces embryo development up to the blastocyst stage (Kind et al., 2005; Harvey et al., 2007). Vascular development during embryonic and fetal growth in utero is triggered by hypoxia (Simon and Keith, 2008).

Oxygen-regulated genes expression plays an important role in pre-implantation embryonic metabolism regulation. Hypoxia Inducible Factor (HIF) regulated by hypoxia oxygen tension is crucial for placenta development. This factor is up-regulated under hypoxic conditions that take place during implantation, fetal placentation, organogenesis, angiogenesis and embryo growth (Adelman et al., 2000). On the other hand, HIF-1 $\alpha$ protein expression can also be induced by other stimuli, for example hormones, cytokines and growth factors (Pringle et al., 2010).

HIF-1 modulates gene transcription by binding to a specific DNA sequence (Hypoxic Response Element (HRE)). HIF-1 is a heterodimer composed of HIF- $1 \alpha$ and HIF- $2 \alpha$ subunits. HIF- $1 \alpha$ and HIF- $2 \alpha$ activate a number of common genes. But HIF- $1 \alpha$ exclusively induces the hypoxic transcription of glycolytic genes such as phosphoglycerate kinase I, aldolase (Wang et al., 2005; Covello et al., 2006).

HIF is the primary molecular sensor which responds to oxygen tension changes (Adelman et al., 1999; 
Maltepe et al., 2005). HIF as transcription factor regulates many cellular processes, for example angiogenesis, invasion, erythropoiesis and cell survival (Semenza, 2000; Bruick, 2003; Covello and Simon, 2004; Cowden Dahl et al., 2005a). But the data about its role in spontaneous abortion is very poor.

To further investigate the role of HIF-la in spontaneous abortion, we measured the HIF-1a gene expression in chorionic tissue and deciduas.

\section{Material and Methods}

Prior to inclusion in the study, all subjects underwent a standard diagnostic work-up. The women were examined using transvaginal ultrasonography for the absence of uterine abnormalities and polycystic ovary syndrome. Women with previously diagnosed arterial hypertension, diabetes, thyroid diseases, autoimmune pathology and infections during pregnancy were excluded from studied population. Women contacting with exogenous risk factors, such as alcohol, electromagnetic radiation, industrial noise, vibration, chemical pollutants were also excluded. The study was approved by the Southern Federal University Bioethics Committee. The participants willingly signed the informed consent. After approval by institutional review board, 9 women (mean age 29) with spontaneous abortion and 8 women (mean age 29) with normally progressing pregnancies were studied.

Samples of chorionic and decidual tissues were taken after surgical termination by curettage of normally progressing pregnancies in 5-9 week of gestation $(\mathrm{n}=8)$ and spontaneous abortion in 5-9 week of gestation $(n=9)$. Villous samples from the control group were obtained from women undergoing elective abortion for social reasons. Samples were stored at $-80^{\circ} \mathrm{C}$ in aliquots for RNA isolation and thawed only once to avoid degradation.

Total RNA isolation was extracted by the acid guanidinium thiocyanate phenol method (Chomczynski and Sacchi, 1987). Upon isolation, RNA was immediately treated with DNAse I (Syntol, Russia). RNA integrity was assessed using non-denaturing $1,5 \%$ agarose gel electrophoresis. Clear $18 \mathrm{~S}$ and $28 \mathrm{~S}$ bands were observed with no signs of RNA degradation. The RNA was reverse transcribed immediately following the RNA isolation and the DNAse treatment using the "RT kit" (Syntol, Russia) with the template denaturation step and the oligo (dT) primer. Reverse transcription (with M-MLV enzyme) was performed during $50 \mathrm{~min}$ incubation at $42^{\circ} \mathrm{C}$ for 50 minutes, followed by duration of $92^{\circ} \mathrm{C}$ for $10 \mathrm{~min}$. cDNA samples were stored at $-20^{\circ} \mathrm{C}$.

Polymerase Chain Reaction (PCR) was performed with commercially available reagents by Syntol (Russia). Sequences of the $H I F-1 \alpha$-specific primers were: forward 5'ATCTCGGCGAAGTAAAGAATCTG-3`; and reverse 5`GTCACCATCATCTGTGAGAACC-3`. Human $\beta$-Actin gene was used as a reference gene. Sequences of the $\beta$ - $\begin{array}{lccc}\text { Actin-specific } & \text { primers } & \text { were: } & 5^{`}- \\ \text { CTTCTACAATGAGCTGGGTG-3 } & \text { and } & 5^{`}-\end{array}$ TCATGAGGTAGTCAGTCAGG-3`. PCR was performed according to the protocol for TerCyc thermocycler (DNK Technologiya, Russia). Cycling parameters for $H I F-1 \alpha$ were the following: 1 cycle: $94^{\circ} \mathrm{C}$ for $10 \mathrm{c} ; 35$ cycles: $94^{\circ} \mathrm{C}$ for $15 \mathrm{c}, 64^{\circ} \mathrm{C}$ for $30 \mathrm{c}$ and $72^{\circ} \mathrm{C}$ for $30 \mathrm{c}$; final elongation: $72^{\circ} \mathrm{C}$ for $2 \mathrm{~min}$.

The PCR products were analyzed by $2 \%$ agarose gel electrophoresis. Gel images were captured using GelDoc XR system (Bio-Rad, USA). Densitometry was performed using Image (NIH, USA). The background was subtracted with the rolling ball radius of 50 pixels.

The intensities of the bands of the target gene $(H I F-1 \alpha)$ was normalized to that of $\beta$-Actin. All experiments were conducted in duplicate. Data were analyzed with MedCalc 11.4.2 software using the appropriate non-parametric Mann-Whitney test. P-value $<0.05$ was considered statistically significant.

\section{Results}

The expression of HIF-1 differs for chorionic and decidual tissues in condition of normal gestation. Compared with decidual tissue, the expression of $H I F-1 \alpha$ was statistically increased in chorionic tissue in condition of normally progressing pregnancy $(\mathrm{P}=0.016)$ (Fig. 1).

$H I F-1 \alpha$ expression in samples of both tissues in spontaneous abortion is equal (Fig. 2). Thus the expression of $H I F-1 \alpha$ in chorionic tissue in case of spontaneous abortion does not match for normal gestation condition.

There wasn't any difference in the level of $H I F-1 \alpha$ expression in decidua in condition of normal pregnancy compared to spontaneous abortion.

Compared with control group, the expression of $H I F-1 \alpha$ was decreased $(1.5$ fold $)$ in chorionic tissue $(\mathrm{P}=0.057)$ in case of spontaneous abortion (Fig. 3).

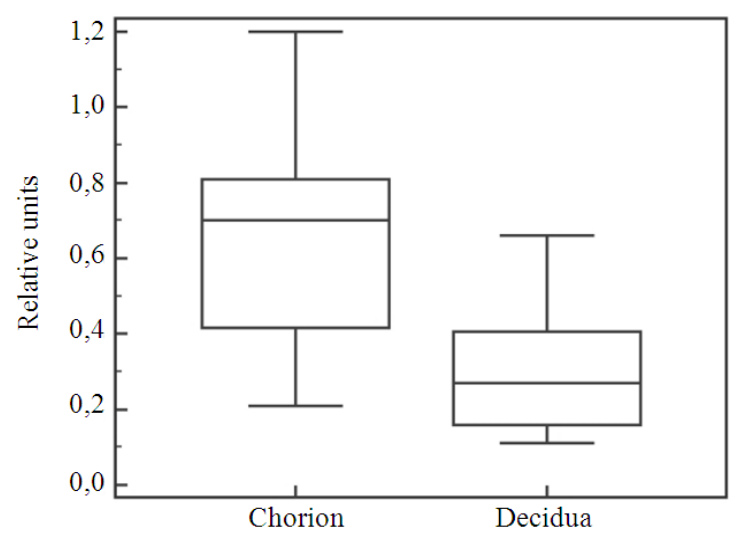

Fig. 1. HIF-1 $\alpha$ expression level in chorionic tissue and decidua in condition of normally progressing pregnancy. Gene expression is provided in the same scale in relative units. The mid-lines are medians and the box lines are 25 th and 75 th percentiles 


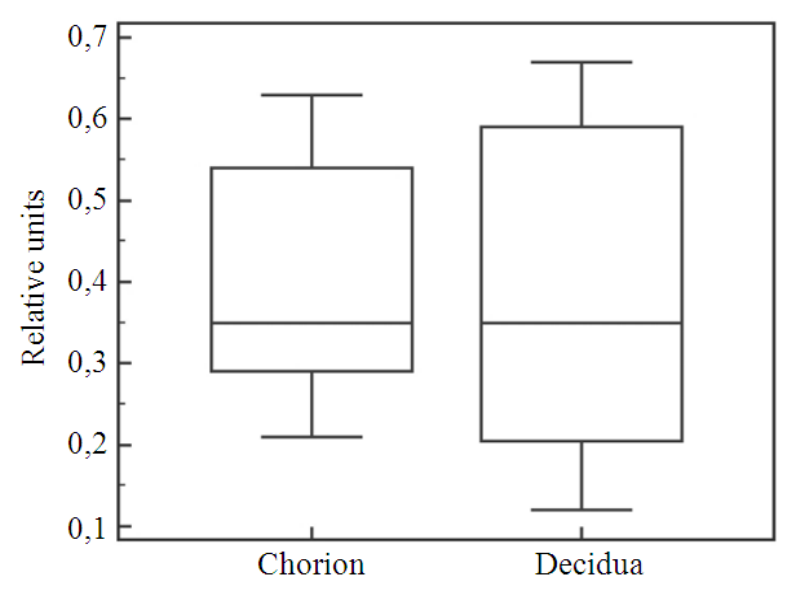

Fig. 2. HIF-1 $\alpha$ expression level in chorionic tissue and decidua in condition of spontaneous abortion. Gene expression is provided in the same scale in relative units. The mid-lines are medians and the box lines are 25 th and 75 th percentiles

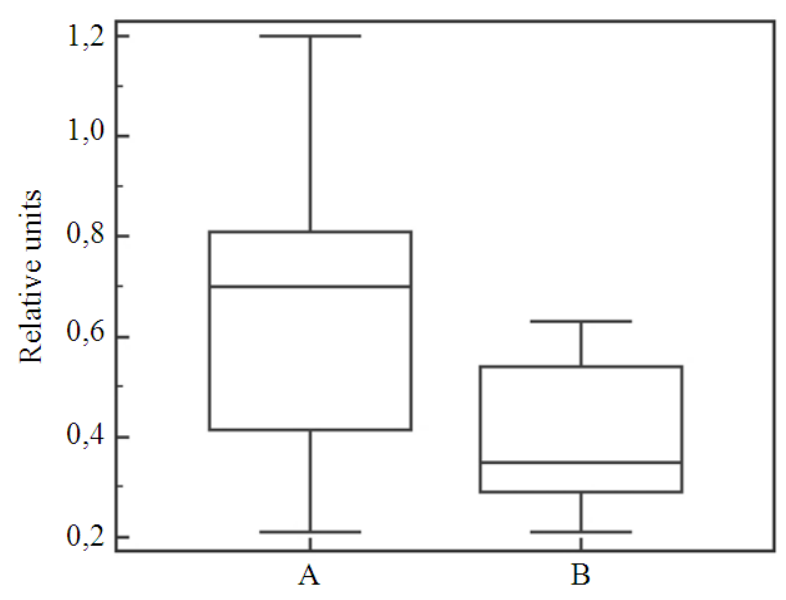

Fig. 3. HIF-1 $\alpha$ expression level in control group (A) and spontaneous abortion (B) in chorionic tissue. Gene expression is provided in the same scale in relative units. The mid-lines are medians and the box lines are 25 th and 75 th percentiles

Thus, the high expression level of the HIF-l $\alpha$ gene in chorionic tissue is characteristic for a normal pregnancy. The decrease in the expression level of $H I F-1 \alpha$ gene in chorionic tissue may be associated with miscarriage in the first trimester.

\section{Discussion}

Our study shows, that during normally progressing pregnancy $H I F-1 \alpha$ expression level in chorionic tissue is significantly increased compared to decidua. In spontaneous abortion $H I F-1 \alpha$ expression in chorionic tissue decreases and reaches values typical for decidua. This may result in trophoblast differentiation alteration, implantation changes, or altered angiogenesis in the forming placenta. Furthermore, as a transcription factor, low levels of HIF may have negative effect on organogenesis and embryo growth. On the other hand, low level of HIF expression may reflect changes in hypoxic environment and active oxygen radicals level increase, which leads to lipid peroxidation intensification, cell membrane damage and cell death. This statement demands further investigation.

During the first trimester of pregnancy placental oxygen remains low. It appears to be necessary for placental metabolic activity and for protecting placental and fetal tissues against toxic oxygen metabolites (Illsley et al., 2010). The invasion of trophoblast cells is regulated by major different factors including signaling of the adhesion and growth factors regulated by the interactions of decidua and trophoblast (Flaminio and Antczak, 2005; Harris, 2010). Hypoxic conditions are the typical factor that regulates the invasion of trophoblast cells which migrate and invade the surrounding blood vessels of the endometrium in the maternal uterus in persisting hypoxic conditions. Hypoxia induces alteration of various genes including integrin, MMP and TIMP (Luo et al., 2011; Onogi et al., 2011; $\mathrm{Na}$ et al., 2012). It was found that the invasion ability of trophoblast is regulated by the expression of $H I F-1 \alpha$ (Dubinsky et al., 2010). The invasive ability of trophoblast cells decreases according to the inhibition of $H I F-1 \alpha$ expression by siRNA (Choi et al., 2012).

$H I F-1 \alpha$ is expressed in syncytiotrophoblast and in villous cytotrpophoblast (Rajakumar, 2000). HIF-1 $\alpha$ mRNA and protein peaked at 7-10 weeks of gestation (Ietta et al., 2006). HIF in hypoxia condition provides a potent stimulus for VEGF synthesis and is essential for development of maternal and placental vasculation in early human pregnancy (Cowden Dahl et al., 2005a; Nau et al., 2002; De Marco and Caniggia, 2002; Daikoku et al., 2003; Qian et al., 2004; Zhang et al., 2009; Arjamaa et al., 2009). $H I F$ expression changes exceeding optimal level lead to pathological processes. There is increase level of HIF expression in choriocarcinoma and other trophoblastic diseases (Bolat et al., 2010).

Defects in HIF are often responsible for early termination of pregnancy (Goldman-Wohl and Yagel, 2002; Sibai et al., 2005). Complete disruption of HIF signaling results in improper placental development (Fryer and Simon, 2006). Homozygosity for a null allele at the mouse Hifl $\alpha$ locus results in embryonic lethality attributable to failed vascularization (Iyer et al., 1998). Cowden Dahl et al. (2005b) reported that HIF-1 $\alpha-H I F-$ $2 \alpha$ knockout mice displayed a $17 \%$ reduction in trophoblast invasion compared with wild type placenta. Several pro- and anti-invasive factors expressed by either the trophoblasts or the decidua were HIF target genes (Cowden Dahl et al., 2005b). These studies 
suggest that HIF appear to act as a key mediator in regulation of placental differentiation, growth and function during early pregnancy.

\section{Conclusion}

Our findings show that a low $H I F-1 \alpha$ expression level in chorionic tissue (close to values, typical for decidua) can be associated with spontaneous abortion in first trimester of pregnancy.

\section{Acknowledgement}

This study was supported by the federal assignment № 6.98.2014/K from Russian Ministry of Science and Education. Research was performed with use of the equipment of Collective Using Center of the Southern Federal University "Biotechnology, Biomedicine and Environmental Monitoring" and "High Technology".

We would like to express our appreciation to Rostovon-Don City Hospital №8 for assistance in collecting the clinical material.

\section{Funding Information}

This study was supported by the federal assignment № 6.98.2014/K from Russian Ministry of Science and Education.

\section{Author's Contributions}

E.V. Mashkina: Conception and design, Acquisition of data, Analysis and interpretation of data, Drafting or revising the article.

K.A. Kovalenko: Analysis and interpretation of data, Contributed unpublished essential data or reagents.

E.V. Butenko: Conception and design, Analysis and interpretation of data, Drafting or revising the article.

\section{Ethics}

We confirm that this manuscript has not been published elsewhere and is not under consideration by another journal. Each author confirms the manuscript represents honest work. All authors have approved the manuscript. Each author agrees with the order in which his name appears on the title page. Study design and methods were approved by Ethics Committee of Southern Federal University.

\section{References}

Adelman, D., M. Gertsenstein, A. Nagy, M. Simon and E. Maltepe, 2000. Placental cell fates are regulated in vivo by HIF-mediated hypoxia responses. Genes Dev., 14: 3191-3203. DOI: 10.1101/gad.853700
Adelman, D., E. Maltepe and M. Simon, 1999. Multilineage embryonic hematopoiesis requires hypoxic ARNT activity. Genes Dev., 13: 2478-2483.

Arjamaa, O., M. Nikinmaa, A. Salminen and K. Kaarniranta, 2009. Regulatory role of HIF-1 alpha in the pathogenesis of Age-related Macular Degeneration (AMD). Age. Res. Rev., 8: 349-358. DOI: 10.1016/j.arr.2009.06.002

Bolat, F., N. Haberal, N. Tunali, E. Aslan and N. Bal et al., 2010. Expression of Vascular Endothelial Growth Factor (VEGF), Hypoxia Inducible Factor 1 alpha (HIF-1alpha) and Transforming Growth Factors betal (TGFbeta1) and beta3 (TGFbeta3) in gestational trophoblastic disease. Pathol. Res. Pract., 206: 19-23. DOI: 10.1016/j.prp.2009.07.017

Bruick, R., 2003. Oxygen sensing in the hypoxic response pathway: Regulation of the hypoxiainducible transcription factor. Genes Dev., 17: 26142623. DOI: $10.1101 / \operatorname{gad} .1145503$

Choi, J., H. Lee, T. Yang and G. Kim, 2012. Effects of hypoxia inducible factors- $1 \alpha$ on autophagy and invasion of trophoblasts. Clin. Exp. Reproductive Med., 39: 73-80. DOI: 10.5653/cerm.2012.39.2.73

Chomczynski, P. and N. Sacchi, 1987. Single-step method of RNA isolation by acid guanidinium thiocyanate-phenol-chloroform extraction. Analytical Biochem., 162: 156-159. DOI: 10.1016/0003-2697(87)90021-2

Covello, K., J. Kehler, H. Yu, J. Gordan and A. Arsham et al., 2006. HIF-2alpha regulates Oct-4: Effects of hypoxia on stem cell function, embryonic development and tumor growth. Genes Dev., 20: 557-570. DOI: 10.1101/gad.1399906

Covello, K. and M. Simon, 2004. HIFs, hypoxia and vascular development. Current Top. Dev. Biol., 62: 37-54. DOI: 10.1016/S0070-2153(04)62002-3

Cowden Dahl, K., B. Fryer, F. Mack, V. Compernolle and E. Maltepe et al., 2005a. Hypoxia-inducible factors $1 \alpha$ and $2 \alpha$ regulate trophoblast differentiation. Molecular Cellular Biol., 25: 10479-10491.

DOI: 10.1128/MCB.25.23.10479-10491.2005

Cowden Dahl, K., S. Robertson, V. Weaver and M. Simon, 2005b. Hypoxia-inducible factor regulates av $\beta 3$ integrin cell surface expression. Molecular Biol. Cell, 16: 1901-1912.

DOI: $10.1091 / \mathrm{mbc} . E 04-12-1082$

Daikoku, T., H. Matsumoto, R. Gupta, S. Das and M. Gassmann et al., 2003. Expression of hypoxiainducible factors in the peri-implantation mouse uterus is regulated in a cell-specific and ovarian steroid hormone-dependent manner: Evidence for differential function of HIFs during early pregnancy. J. Biol. Chem., 278: 7683-7691. DOI: $10.1074 /$ jbc.M211390200 
De Marco, C. and I. Caniggia, 2002. Mechanisms of oxygen sensing in human trophoblast cells. Placenta, 23: S58-S68. DOI: 10.1053/plac.2002.0809

Dubinsky, V., T. Poehlmann, P. Suman, T. Gentile and U. Markert et al., 2010. Role of regulatory and angiogenic cytokines in invasion of trophoblastic cells. Am. J. Reproductive Immunol., 63: 193-199.

DOI: $10.1111 / \mathrm{j} .1600-0897.2009 .00778 . \mathrm{x}$

Flaminio, M. and D. Antczak, 2005. Inhibition of lymphocyte proliferation and activation: A mechanism used by equine invasive trophoblast to escape the maternal immune response. Placenta, 26: $148-159$.

DOI: $10.1016 /$ j.placenta.2004.05.008

Fryer, B. and M. Simon, 2006. Hypoxia, HIF and the placenta. Cell Cycle, 5: 495-498.

DOI: $10.4161 /$ cc.5.5.2497

Giaccia, A., M. Simon and R. Johnson, 2004. The biology of hypoxia: The role of oxygen sensing in development, normal function and disease. Genes Dev., 18: 2183-2194. DOI: 10.1101/gad.1243304

Goldman-Wohl, D. and S. Yagel, 2002. Regulation of trophoblast invasion: From normal implantation to preeclampsia. Molecular Cellular Endocrinol., 187: 233-238.

DOI: $10.1016 / \mathrm{S} 0303-7207(01) 00687-6$

Harris, L., 2010. Review: Trophoblast-vascular cell interactions in early pregnancy: How to remodel a vessel. Placenta, 31: S93-S98.

DOI: $10.1016 /$ j.placenta.2009.12.012

Harvey, A., A. Santos, M. Kirstein, K. Kind and B. Fischer et al., 2007. Differential expression of oxygen-regulated genes in bovine blastocysts. Molecular Reproduct. Dev., 74: 290-299. DOI: $10.1002 / \mathrm{mrd} .20617$

Ietta, F., Y. Wu, J. Winter, J. Xu and J. Wang et al., 2006. Dynamic HIF1a regulation during human placental development. Biol. Reproduct., 75: 112121. DOI: $10.1095 /$ biolreprod.106.051557

Illsley, N., I. Caniggia and S. Zamudio, 2010. Placental metabolic reprogramming: Do changes in the mix of energy-generating substrates modulate fetal growth? Int. J. Dev. Biol., 54: 409419. DOI: $10.1387 / \mathrm{ijdb} .082798 \mathrm{ni}$

Iyer, N., L. Kotch, F. Agani, S. Leung and E. Laughner et al., 1998. Cellular and developmental control of $\mathrm{O} 2$ homeostasis by hypoxia-inducible factor $1 \alpha$. Genes Dev., 12: 149-162.

Kind, K., R. Collett, A. Harvey and J. Thompson, 2005. Oxygen regulated expression of GLUT 1, GLUT 3 and VEGF in the mouse blastocyst. Molecular Reproduct. Dev., 70: 37-44.

DOI: $10.1002 / \mathrm{mrd} .20183$
Luo, J., F. Qiao and X. Yin, 2011. Hypoxia induces FGF2 production by vascular endothelial cells and alters MMP9 and TIMP1 expression in extravillous trophoblasts and their invasiveness in a cocultured model. J. Reproduct. Dev., 57: 8491. DOI: $10.1262 /$ jrd.10-008K

Maltepe, E., G. Krampitz, K. Okazaki, K. Red-Horse and W. Mak et al., 2005. Hypoxia-inducible factor-dependent histone deacetylase activity determines stem cell fate in the placenta. Development, 132: 3393-3403. DOI: $10.1242 / \mathrm{dev} .01923$

Na, K., H. Lee, J. Choi, J. Eun and S. Nam et al., 2012. Dynamic alterations in integrin alpha4 expression by hypoxia are involved in trophoblast invasion during early implantation. J. Cellular Biochem., 113: 685-694. DOI: 10.1002/jcb.23398

Nau, P., T. Van Natta, J. Ralphe, C. Teneyck and K. Bedell et al., 2002. Metabolic adaptation of the fetal and postnatal ovine heart: Regulatory role of hypoxia-inducible factors and nuclear respiratory factor-1. Pediatric Res., 52: 269-278. DOI: $10.1203 / 00006450-200208000-00021$

Onogi, A., K. Naruse, T. Sado, T. Tsunemi and H. Shigetomi et al., 2011. Hypoxia inhibits invasion of extravillous trophoblast cells through reduction of Matrix Metalloproteinase (MMP)-2 activation in the early first trimester of human pregnancy. Placenta, 32: 665-670.

DOI: $10.1016 /$ j.placenta.2011.06.023

Patel, J., K. Landers, R. Mortimer and K. Richard, 2010. Regulation of Hypoxia Inducible Factors (HIF) in hypoxia and normoxia during placental development. Placenta, 31: 951-957. DOI: $10.1016 /$ j.placenta.2010.08.008

Pringle, K., K. Kind, A. Sferruzzi-Perri, J. Thompson and C. Roberts, 2010. Beyond oxygen: Complex regulation and activity of hypoxia inducible factors in pregnancy. Human Reproduct. Update, 16: 415-431. DOI: 10.1093/humupd/dmp046

Qian, D., H. Lin, H. Wang, X. Zhang and D. Liu et al., 2004. Normoxic induction of the hypoxic-inducible factor- $1 \alpha$ by interleukin- $1 \beta$ involves the extracellular signal-regulated kinase $1 / 2$ pathway in normal human cytotrophoblast cells. Biol. Reproduct., 70: 18221827. DOI: 10.1095/biolreprod.103.025031

Rajakumar, A., 2000. Conrad KP. Expression, ontogeny and regulation of hypoxia-inducible transcription factors in the human placenta. Biol. Reproduct., 63: 559-569. DOI: 10.1095/biolreprod63.2.559

Renaud, S., T. Cotechini, J. Quirt, S. MacdonaldGoodfellow and M. Othman et al., 2011. Spontaneous pregnancy loss mediated by abnormal maternal inflammation in rats is linked to deficient uteroplacental perfusion. J. Immunol., 186: 17991808. DOI: $10.4049 /$ jimmunol.1002679 
Semenza, G., 2000. HIF-1 and human disease: One highly involved factor. Genes Dev., 14: 19831991. DOI: $10.1101 /$ gad.14.16.1983

Sibai, B., G. Dekker and M. Kupferminc. 2005. Preeclampsia. Lancet, 365: 785-799. DOI: $10.1016 / \mathrm{S} 0140-6736(05) 17987-2$

Simon, M. and B. Keith, 2008. The role of oxygen availability in embryonic development and stem cell function. Nat. Rev. Molecular Cell Biol., 9: 285296. DOI: $10.1038 / \mathrm{nrm} 2354$
Wang, V., D. Davis, M. Haque, L. Huang and R. Yarchoan, 2005. Differential gene up-regulation by hypoxia-inducible factor- $1 \alpha$ and hypoxia-inducible factor- $\alpha$ in HEK293T cells. Cancer Res., 65: 32993306. DOI: 10.1158/0008-5472.CAN-04-4130

Zhang, P., X. Zhang, X. Hao, Y. Wang and Y. Hui et al., 2009. Racl activates HIF-1 in retinal pigment epithelium cells under hypoxia. Graefe's Arch. Clin. Exp. Ophthalmol., 247: 633-639.

DOI: $10.1007 / \mathrm{s} 00417-008-1031-0$ 